This item was submitted to Loughborough's Research Repository by the author.

Items in Figshare are protected by copyright, with all rights reserved, unless otherwise indicated.

\title{
Divergence and convergence in graphic design and communication design
}

PLEASE CITE THE PUBLISHED VERSION

http://www.drs2018limerick.org/participation/conversations

\section{PUBLISHER}

Design Research Society

\section{VERSION}

VoR (Version of Record)

\section{PUBLISHER STATEMENT}

This work is made available according to the conditions of the Creative Commons Attribution-NonCommercialShareAlike 4.0 International (CC BY-NC-SA 4.0) licence. Full details of this licence are available at: http://creativecommons.org/licenses/by-nc-sa/4.0/

\section{LICENCE}

CC BY-NC-SA 4.0

\section{REPOSITORY RECORD}

Harland, Robert G., Veronika Kelly, Karel van der Waarde, and Eamon Spelman. 2019. "Divergence and Convergence in Graphic Design and Communication Design". figshare. https://hdl.handle.net/2134/35404. 


\title{
Divergence and convergence in graphic design and communication design
}

\begin{abstract}
Academics have recently explored establishing two education networks in graphic design and communication design, one respectively in the UK and the other in Australia. However, although based on similar concerns, beliefs and aspirations, the two networks have assumed different names.

For some, graphic design and communication design are interchangeable terms. For others, they mean different things. This may be confusing for some in a higher education sector that has continually evolved and expanded in recent decades.

This 'conversation' session set out to explore the similarities and differences between graphic design and communication design. The formation of these networks was briefly outlined and delegates worked together to identify how various defining qualities competencies, knowledge, skills, activities, functions - might differentiate between graphic design and communication design.

The objective was to establish where there are converging and diverging interests, and where there needs to be further research into differentiation that challenges territorial assumptions about practice, theory, and history in graphic design and communication design.
\end{abstract}

Keywords: graphic design; communication design; pedagogy; research

\section{Convenors Information}

\begin{tabular}{lll}
\hline Convenors Name & Email & Affiliation \\
\hline $\begin{array}{l}\text { Robert Harland } \\
\text { (Lead and Contact) }\end{array}$ & r.g.harland@lboro.ac.uk & Loughborough University \\
\hline Veronika Kelly & veronika.kelly@unisa.edu.au & University of South Australia \\
& & \\
\hline Karel van der Waarde & waarde@glo.be & Swinburne University of \\
& & $\begin{array}{l}\text { Technology, Melbourne + } \\
\text { Basel School of Design. }\end{array}$ \\
\hline Eamon Spelman & eamon.spelman@lit.ie & Limerick Institute of \\
& & Technology \\
\hline
\end{tabular}




\section{Organising question(s) or provocation(s)}

The session aimed to bring design educators and researchers together in an engaging dialogue about the ambiguity between graphic design and communication design.

An overarching question guided the organisation of the conversation session:

What are the similarities and differences between graphic design and communication design?

Additional sub-questions shaped the focus of the conversation:

How are these similarities and differences represented in curriculum design?

What are the convergent and divergent design research agendas in these disciplines?

What are the direct consequences of the ambiguity for design researchers?

Where and who are the respective design practice communities?

\section{The DRS2018 Conversation session}

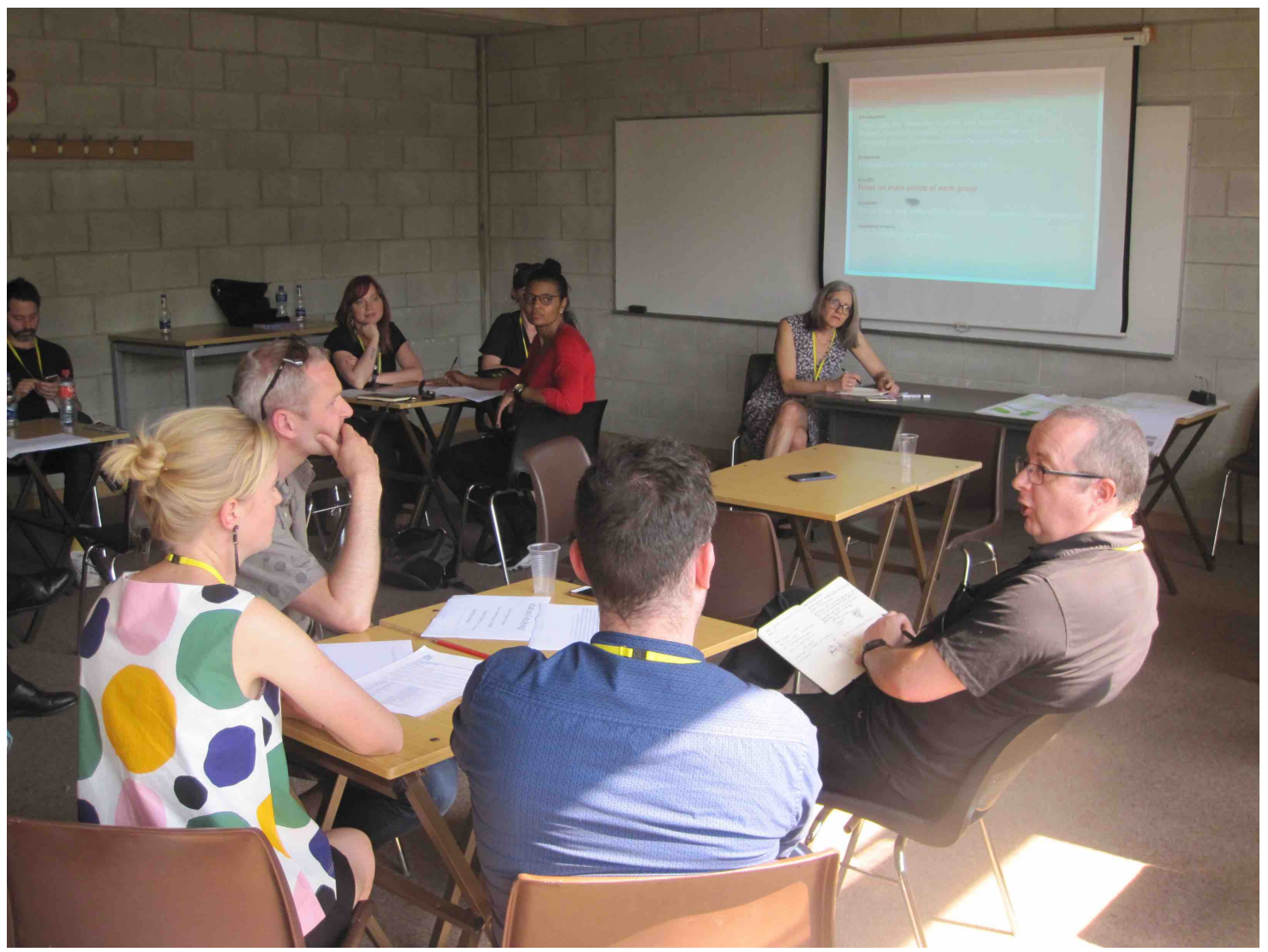

Figure 1: Participants share the key points that arose in their group discussion

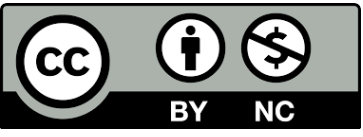

This work is licensed under a Creative Commons Attribution-NonCommercialShare Alike 4.0 International License. https://creativecommons.org/licenses/bync-sa/4.0/ 


\section{Participants}

The workshop session was planned for approximately 90 minutes. Of the 32 people who signed up to attend, 16 people actually participated. While more than half the participants were from the United Kingdom and Ireland, Barbados, Australia, Switzerland, Finland and Qatar were also represented. The participants were:

Nicola St John, Swinburne University of Technology, Australia

Glen O'Sulllivan, Rubix Design, Ireland

Shelley Mayers, Barbados Community College, Barbados

Emily Corrigan-Kavanagh, Surrey University, United Kingdom

Brenda Duggan, Dublin Institute of Technology, Ireland

Paulo Dziobczenski, Aalto University, Finland

James Corazzo, Sheffield Hallam University, United Kingdom

Denielle Emans, Virginia Commonwealth University, Qatar

Joe Lane, Limerick Institute of Technology, Ireland

Stella Hackett, Barbados Investment and Development Corporation, Barbados

Simon Downs, Loughborough University, United Kingdom

Denise McEvoy, Dún Laoghaire Institute of Art, Design and Technology, Ireland

Claire Lerpiniere, De Montfort University, United Kingdom

Steve Rigley, Glasgow School of Art, United Kingdom

Michael Renner, Basel School of Design, Switzerland

Jean Paul Dowling, National College of Art and Design, Ireland

\section{Set up of the space and structure of session}

The room set up involved six tables in groups for four, each displaying a range of topics set out on cue cards (see examples in Figures 2-5). The cue cards have since been made available for download at: https://doi.org/10.17028/rd.Iboro.6865238. Upon arrival participants were encouraged to read the topics and select where to sit based on the issues they were interested in. The session began with van der Waarde introducing two short presentations by Harland and Kelly, respectively explaining the formation of two networks: Graphic Design Educators' Network (GDEN) and Communication Design Educators' Network (CDEN). This provided some context for the workshop and encouraged delegates to consider research and practice in graphic design and communication design. As noted above, participants self-organised into groups of four and each group responded to issues set out on cards designed to facilitate discussion about similarities and differences between graphic design and communication design. These were designed to cover competencies, knowledge, skills, activities, functions. The session convenors were available to informally join in with group discussion but mostly the groups functioned independently. The discussions were recorded on three smart phones that were circulated to sample the nature of conversations. Each group then communicated the essence of their discussion to other session delegates, leading to open conversation about similarities and differences between graphic design and communication design, led by Harland and Kelly. Van der Waarde closed the session with some concluding remarks. 


\title{
what am I studying?
}

\author{
Communication Design \\ Visual Communication Design \\ Graphic Design \\ Advertising Design
}

Figure 2: Sample DRS2018 Conversation card number 2

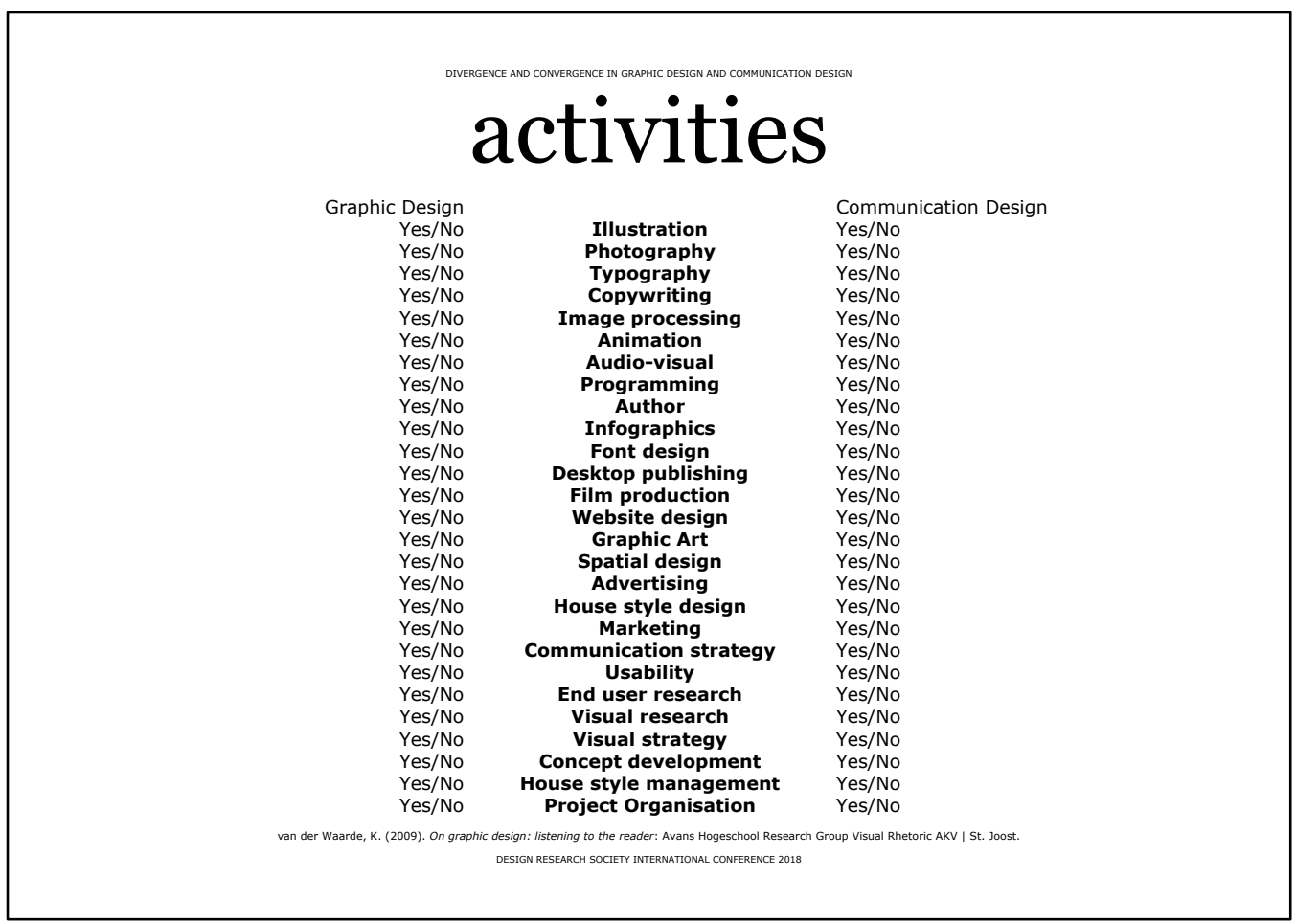

Figure 3: Sample DRS2018 Conversation card number 4 


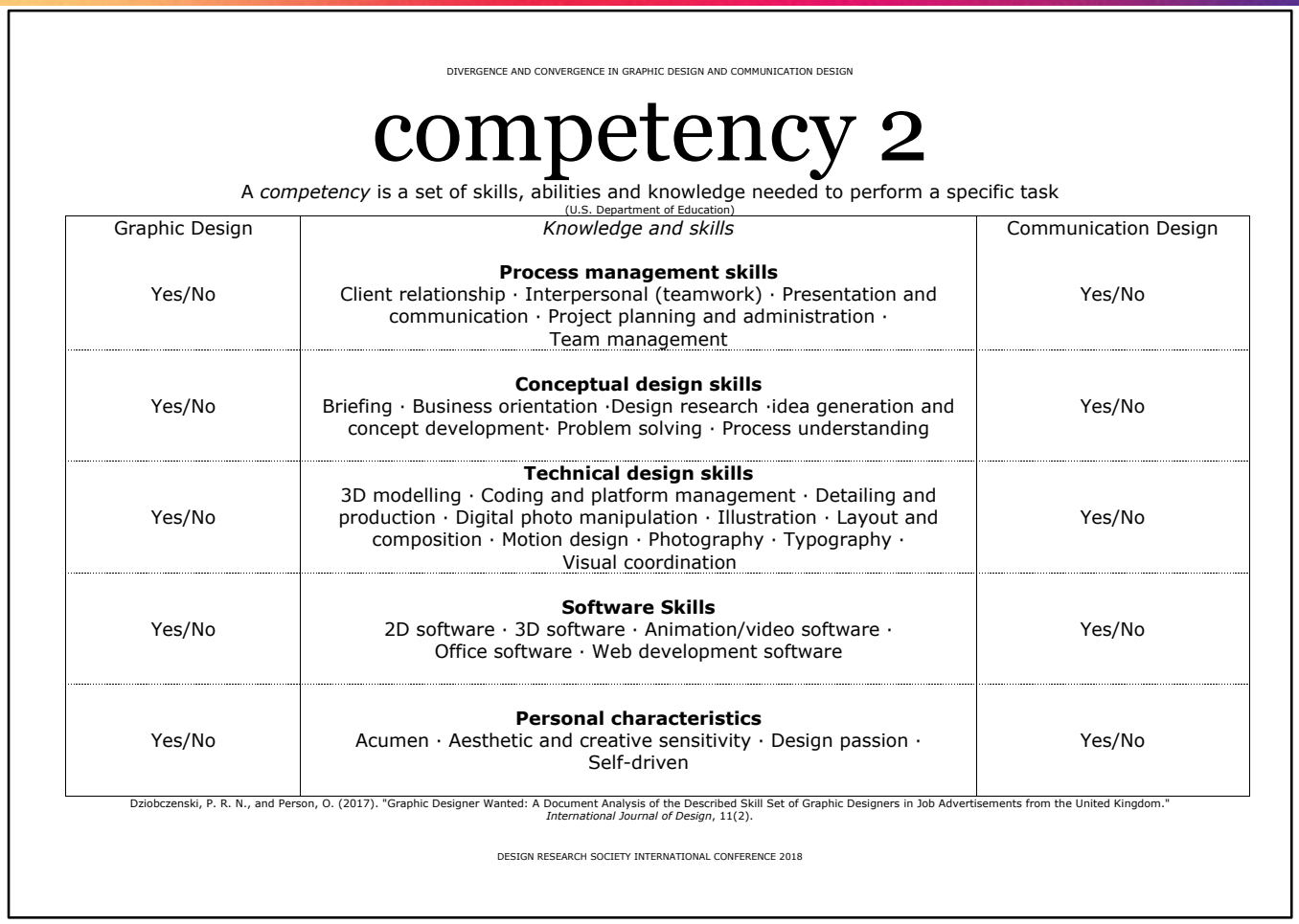

Figure 4: Sample DRS2018 Conversation card number 9

\section{opinion 2}

... the term 'communication design' is synonymous with 'graphic design'.

Sue Walker (2017) Research in Graphic Design, The Design Journal, 20:5,
549-559, DOI: 10.1080/14606925.2017.1347416

True or false?

Figure 5: Sample DRS2018 Conversation card number 13 
What discussions, activities and experiences took place

The introduction by the three convenors elaborated on some key issues (Spelman was unable to attend due to personal circumstances). Van der Waarde presented a further set of questions. Are the terms graphic design and communication design the same in different countries? Are they different in the same country? What do programmes in each area actually teach? What do the teachers research? What journals do academics publish in?

Harland explained that the Graphic Design Educators' Network had formed, in part, because of a lack of continuity between various graphic design events over a period of time. He cited a prophetic statement from 1990 that 'access, expansion and increasing diversity ... could threaten the essential cohesion ... of graphic design' (CNAA 1990), and yet graphic design now identifies the highest number of programmes in UK Higher Education, despite considerable diversification. This was supplemented by a provocation drawn from Walter Benjamin: 'Putting one's job into words is part of the skill required to perform it' (Benjamin 2008 [1936]: 23). Kelly explained how the graphic design industry in Australia had lacked appetite for critical discourse, and that most larger public universities had shifted to renaming programmes in graphic design as communication design. The inaugural forum of the Communication Design Educators' Network first confronted two questions: What are university design degrees good for? How do we educate design practitioners for the future? She set out the four key concerns identified by senior design academics from across Australia: promotion and advocacy; networking; publication, research and academic collaboration; accreditation.

Recordings of the group conversations confirm that the discussions were content-rich and explored the issues from a number of differing perspectives. These will not be reported fully here, but a snapshot across the different groups, summarized below, reveals a deep capacity for self-reflection and breadth of understanding.

Most believed communication design to encompass a wider range of disciplinary perspectives, from illustration, advertising, photography or sound design. This is especially appealing for specialist practices such as illustration, whose practitioners may be comfortable identifying with this in part because of not wanting to be associated with graphic design. Communication design also has appeal as a humanities subject because of its close association with media studies.

Occasionally, prominent design commentators such as Victor Margolin (2002) were referenced as a starting point for understanding graphic design as a professional practice, whereas visual communication can be understood as a basic human activity in which everyone engages, and is hundreds of thousands of years old. Such comments also reflected how communication design was occasionally substituted for visual communication.

Institutional structures were also discussed. In one instance, what had been a graphics, illustration and photography department, had become visual communication, and now communication design. And yet students still saw themselves as graphic designers, illustrators, photographers! In other cases, visual communication had proved difficult, and there had been a concerted effort to move back towards graphics because prospective 
students understood what it meant and alumni confirmed that industry was much more familiar with the term. At the same time, while graphic design was seen as more familiar with students coming into higher education, once students were studying in a programme they grew to consider themselves more as just 'designers'. Graphic design communication, graphic communication design, visual communication design were provided as further evidence, from across Europe, of other options. The simple analogy of a taxi journey was explained in one discussion: when a taxi driver asks you what you do, visual communicator means nothing, but graphic designer means something.

In one case, a post-doctoal researcher explained how they were employed as a communications designer but actually did interaction design. This led to further questions. Is interaction design embedded in visual communication? It's not in graphic design, which may be thought of as somethng more traditional aligned with illustration, typography, book design, or print design. In order to create design interaction you need some graphic design. You need visual communication. No, you need communication. Communication is not just about designing visual content, it is also about designing experiences, designing behaviours. Communication has become broader and broader as design is getting bigger and bigger.

A similarity was made with product design that has resisted shifting from that name despite work produced by these designers being less about materiality, and increasingly concerned with interaction, service and functionality, or user-experience design - leading to the assumption that those working in these fields must have studied product design!

In another case, it was claimed that we think of graphic as form; it has an aesthetic and is tangible. Graphic is inscription. You can see it. You can make a mark on screen in that typography is visual, dealing with graphics, but most significantly, dealing with mark making.

One of the most focused and structured group discussions benefitted from close alignment with the statements provided on the tables. It was all the more interesting for the presence of two textile design participants, and participants from Barbados. This encouraged discussion about the less mature development of graphic design in a region where more recent practices such as transition design, or design thinking, are not yet on the radar. There emerged crossover between textiles and graphics in areas such as print and visual merchandising, or multimedia design, and Textiles students quite often moved into graphics, becoming website designers. However, it was acknowledged that textile designers' typographic skills were undeveloped and graphic designers did not know how to generate patterns for surface design. This all became more relevant when communication design was considered to be a useful phrase to capture this breadth of activity, leading to graphic design being considered a subset of communication design.

As noted, this group fulfilled the task more than others regarding using the prompts on the cue cards. Their discussion about competencies stimulated much debate and lines of inquiry, and the participants used the card to structure their discussion (Figure 6). 


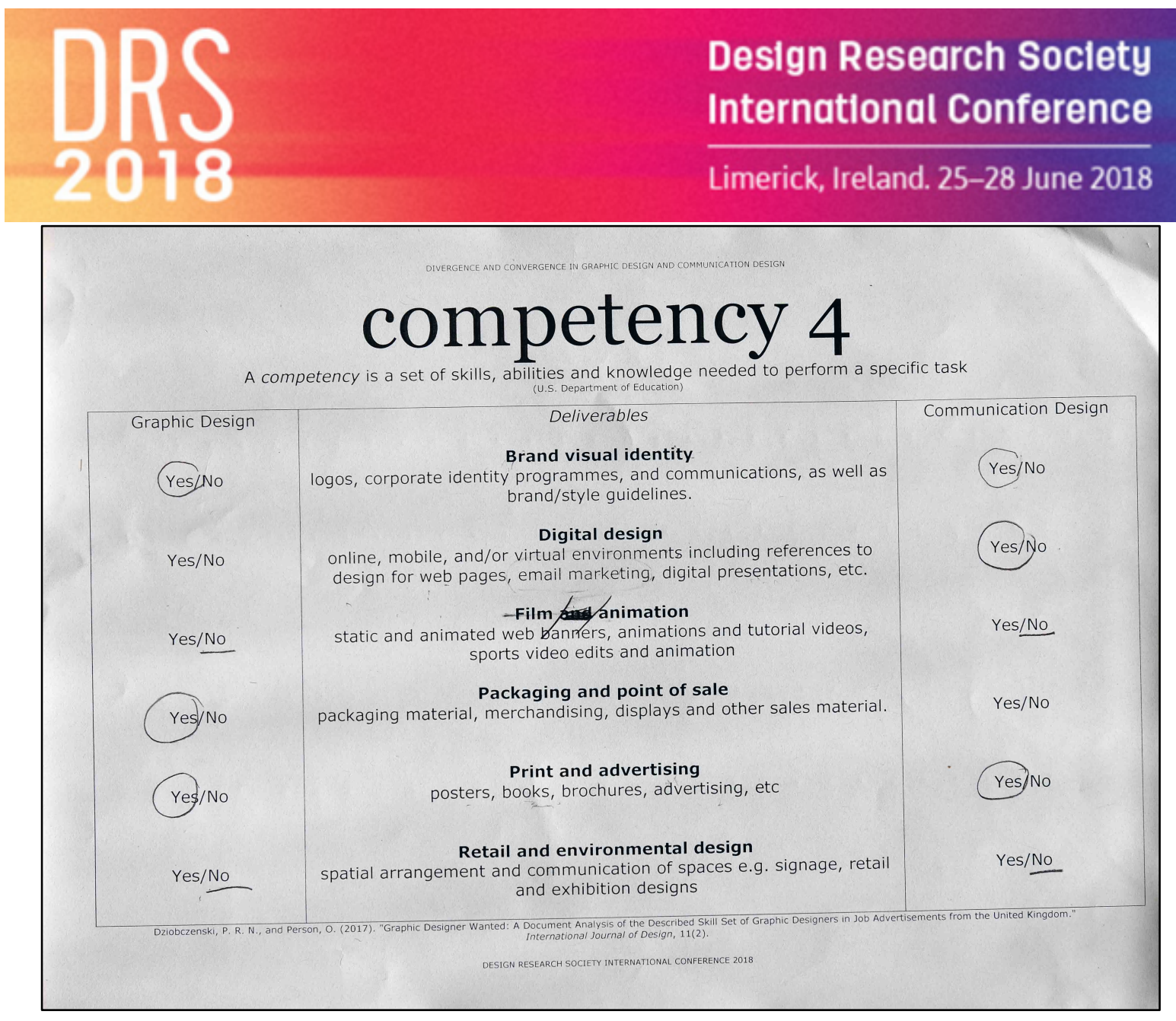

Figure 6: Completed DRS2018 Conversation card number 11

Working from a card structured against recently published research (Dziobczenski and Person 2017) the group very quickly they made a differentiation between core skills and others that are more specialised. Brand visual identity was thought to be of relevance to both graphic design and communication design, whereas digital design was thought to be more aligned with the latter, suggesting graphic design to be more associated with analogue media. Film and animation were thought to relate to neither: 'film and animation should be film and animation'! These were both thought to have separate identities with established degrees in their own right, and the matter of expertise arose with regard to the risk of dabbling. This contrasted with the competency packaging and point of sale, which was thought to be 'classic graphics'. The merchandising aspect of this sparked the earlier mentioned point about how textile design also claims visal merchandising as a core area of student activity. Conversely, print and advertising satisfied both fields, whereas retail and environmental design were thought to fit comfortably with neither. Similar to film and animation, this has a strong independent identity that could easily be taught as part of an interior design degree, and its specialist interest in retail environment design.

This sub-group concluded that graphic design and communication design were significantly different. Graphic design displays much expertise in the visual and crafting of an artefact. It may be considered a subset of communication design and provide a foundation for digital design. Some competencies such as packaging and point of sale might be considered 'classic' examples of graphic design and provide a good indicator of a discipline that is

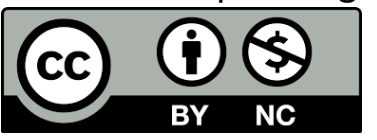

This work is licensed under a Creative Commons Attribution-NonCommercialShare Alike 4.0 International License. https://creativecommons.org/licenses/bync-sa/4.0/ 
outcome led. Similarly, print and advertising has dual appeal. Communication design was thought to be broader, and more concept and solution driven. Context and culture are important and thought to more embrace digital design (Figures 7 and 8).

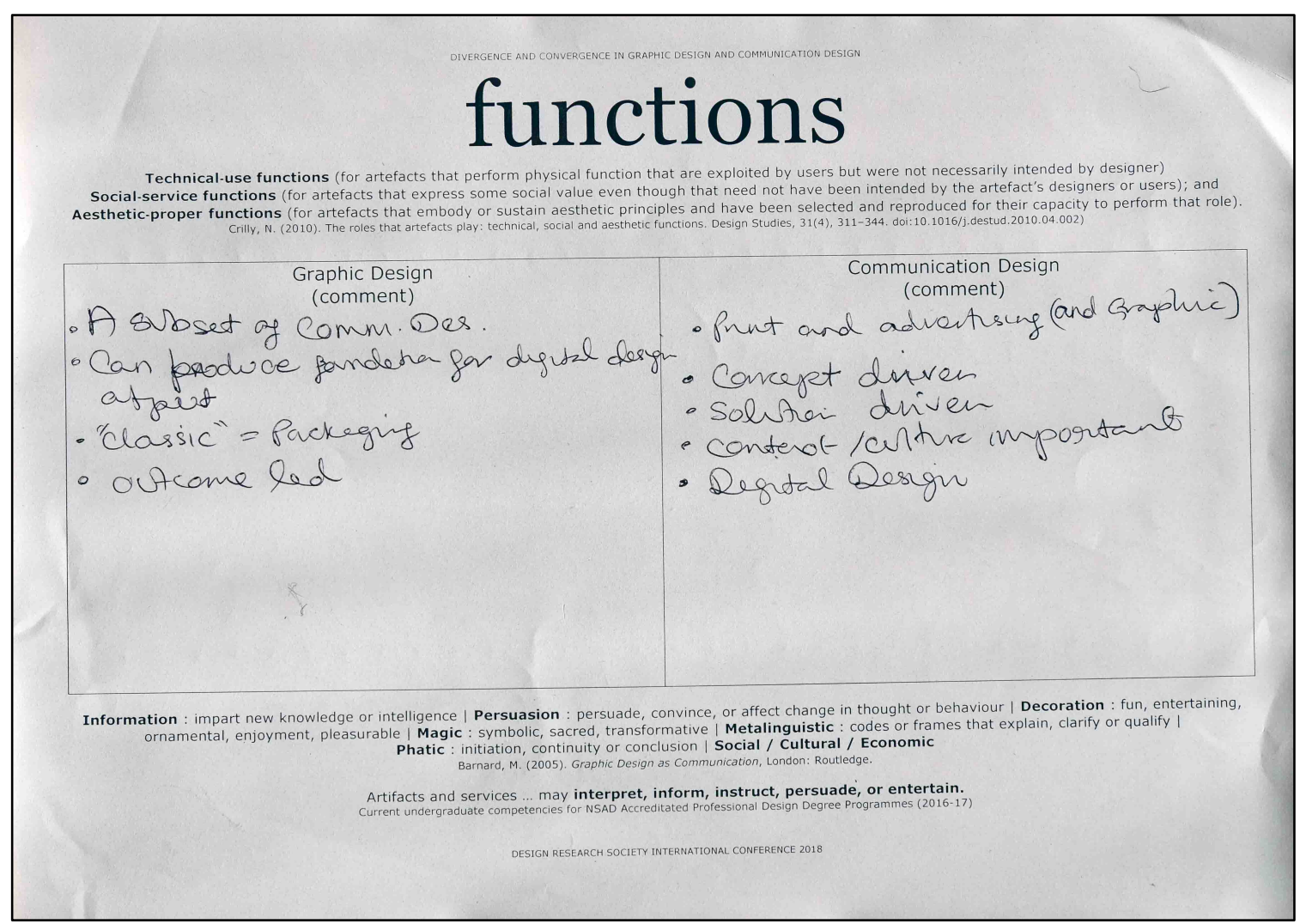

Figure 7: Completed DRS2018 Conversation card number 13 


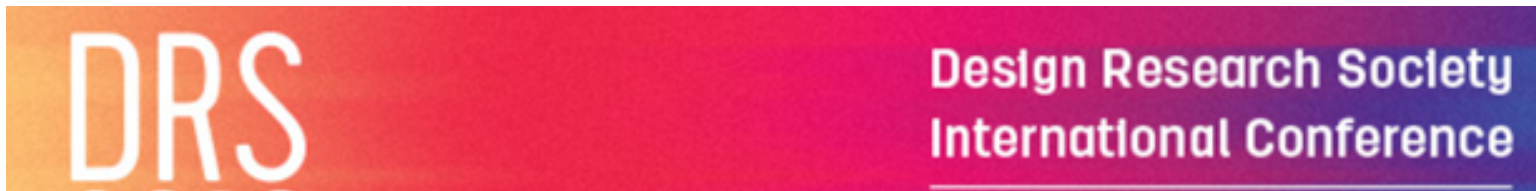

Limerick, Ireland. 25-28 June 2018

\section{opinion}

the term 'communication design' is synonymous with 'graphic design'.
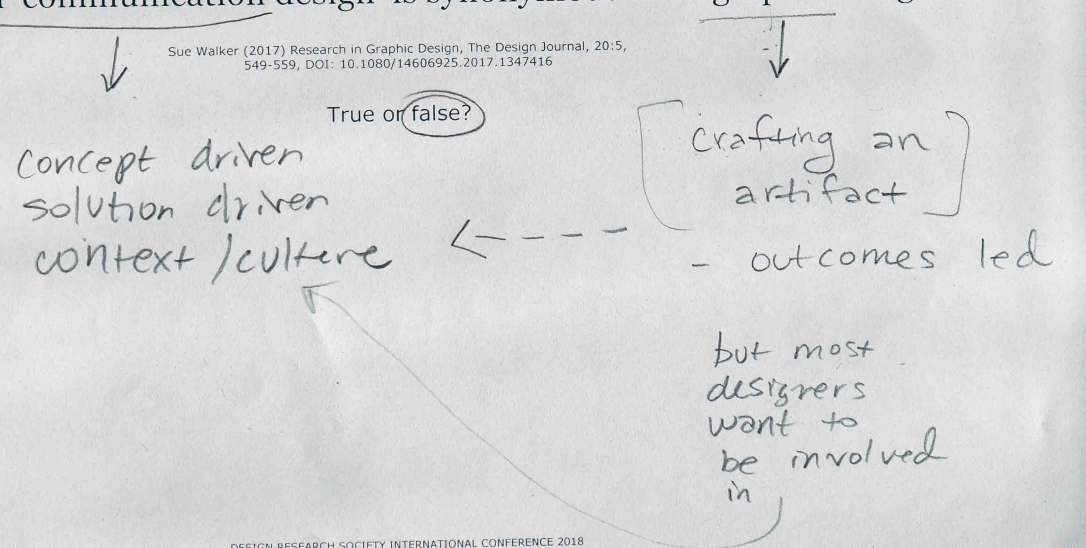

DESIGN RESEARCH SOCIETY INTERNATIONAL CONFERENCE 2018

Figure 8: Completed DRS2018 Conversation card number 13

Critical reflection on the session and future directions

The question about the similarities and differences between graphic design and communication design remains unanswered in sufficient depth to challenge prevailing misconceptions that they are synonymous with each other. But there is certainly a sense that there is difference. This brief portrayal illustrates this point, and the cue cards made available for this workshop session stimulated serious and indepth discussion enough to suggest there is work to be done by these respective design practice and research communities. Other terminologies, such as visual communication remain in use, often substituting for either term, and other variations will no doubt emerge with the next technological shift. Further research is needed to make comparisons at curriculum level to determine a continuum of change between one and the other. With this in mind, further research is also likely to reveal where there is harmony. Communication design in Australia is assumed to be embedded as a practice, meaning fewer major universities with large programmes name graphic design in its own right. However, under the umbrella term of communication design, these curriculums continue to incorporate many of the competencies and functions discussed in this workshop. This is different in the UK where there is great diversification and nuanced understandings of different programme nomenclature. This diversity poses challenges for academics to report the research undertaken that underpins revisions to syllabus, and programme titles, to mitigate the increased lack of cohesion in a field of study, arguably the largest in art and design. 
The overriding conclusion from the session is that graphic design and communication design are not synonymous with each other, and it is in neither's interest for these to be interchangeable terms. Taking Benjamin as a cue, a more skilful use of words is required to explain the deeds associated with each of these distinct practices.

\section{References}

Barnard, M. (2005). Graphic Design as Communication, London: Routledge.

Benjamin, W. (2008 [1936]). The Work of Art in the Age of Mechanical Reproduction, London: Penguin Books Limited.

Bonsiepe, G. (1994). "A Step Towards the Reinvention of Graphic Design." Design Issues, 10(1), 47-52.

CNAA. (1990). Vision and change: a review of graphic design studies in polytechnics and colleges., London: Council for National Academic Awards.

Crilly, N. (2010). The roles that artefacts play: technical, social and aesthetic functions. Design Studies, 31(4), 311-344. doi:10.1016/j.destud.2010.04.002)

Drucker, J. (2014). Graphesis: Visual Forms of Knowledge Production, Harvard University Press: London, England and Cambridge, Massachusetts.

Dziobczenski, P. R. N., and Person, O. (2017). "Graphic Designer Wanted: A Document Analysis of the Described Skill Set of Graphic Designers in Job Advertisements from the United Kingdom." International Journal of Design, 11(2).

Frascara, J. (2004). Communication Design: Principles, Methods, and Practices, New York: Allworth Press.

Harland, R. G., (2018). Divergence and convergence in graphic design and communication design: conversation cue cards. Available at https://doi.org/10.17028/rd.Iboro.6865238, Accessed 5 August 2018

Icograda Design Education Manifesto, Taipei 2011, Available at: http://www.ico-d.org/database/files/library/lcogradaEducationManifesto_2011.pdf, Accessed 5 August 2018

Margolin, V. (2002). The Politics of the Artificial: Essays on Design and Design Studies, Chicago: University of Chicago Press.

NSAD Accredited Professional Design Degree Programmes (2016-17), Available at: https://educators.aiga.org/wp-content/uploads/2017/08/NASAD-COMPETENCIES.pdf, Accessed 5 August 2018

Walker, S., (2017) Research in Graphic Design, The Design Journal, 20:5, 549-559, DOI: 10.1080/14606925.2017.1347416

van der Waarde, K. (2009). On graphic design: listening to the reader: Avans Hogeschool Research Group Visual Rhetoric AKV | St. Joost. 